\title{
Cognition and markets
}

Brian J. Loasby

\section{Introduction}

Whether as an explanation of decision making or as a guide to making decisions, rational choice theory is not very interesting. What is called 'a decision' is merely the logical precipitate of the premisses: everything that might be regarded as a determinant of choice is already in place, and assumed to be known (if only as a probability distribution) to the chooser. Within choice theory agents make no decisions. Now this should not be a source of complaint, for, paradoxical as it may seem, choice theory is not about decision making. Its purpose is to provide an essential element in constructing theories of equilibrium, and equilibrium in economics is routinely defined as a state of affairs in which there are no decisions to be made. In fact, analysis often proceeds - notably in the Arrow-Debreu model - directly from basic data to equilibrium allocations.

When choices are deduced, only the premisses matter; and so it is the explanation of those determinants - and why they, and only they, are determinants - that deserves attention. One might therefore have expected economists to have shared Herbert Simon's view (1976: xii) that the premisses should be the unit of analysis; but even though it is standard practice to explain differences in behaviour, including changes in behaviour over time, by differences in the premisses from which behaviour is deduced - usually differences in opportunity sets, and often with specific emphasis on incentive structures - these differences are not themselves investigated. The reason is that decision premisses are assumed to reflect precisely the fundamentals of economic analysis; they are therefore innocuous. (There are a few exceptions, such as the theory of speculative bubbles.) Consequently it is not accidental that few economists pay specific attention to organisational forms, because in equilibrium models any organisational structure must be transparent to the basic data; and it is notable that orthodox and quasi-orthodox economists who have tried to explain why firms, as organisations, exist have taken care to isolate their explanations from the theory of production, which continues to be directly based on the supposedly fundamental data of the economy. As Coase (1991, p. 65) has pointed out, this has led economists 'to neglect the main activity of 
a firm, running a business'. In a rational choice equilibrium, running a business is a trivial activity: production functions are public knowledge, and productive skills are incorporated in the specification of inputs.

Simon, however, believes that decision premisses are problematical and yet capable of investigation by observation and experiment, and furthermore that organisational design is a significant influence on the premisses that are used in various parts of an organisation. To understand organisational behaviour, therefore, it is not sufficient to postulate rationality in the peculiarly restricted sense that is used in much economic theory (though it is normally appropriate to postulate intelligent and purposive behaviour); one needs to investigate the procedures by which occasions for decision are identified, options are sought and examined, and choices made; and this investigation should pay particular attention to the premisses which guide these procedures.

In this chapter my primary concern is not the firm but the individual, though there is a need to consider the activities of firms. But this brief excursion into organisational design is not irrelevant, because in considering the individual as decision maker particular attention has to be paid to the ways in which individual knowledge is organised, and to the decision premisses which shape both the development and use of that individual knowledge. In accordance with the title, I give some emphasis to the influence of markets on the growth and use of individual knowledge and also note how knowledge within firms may benefit from market relationships. I begin by identifying some basic elements of human cognition to provide a credible psychological basis for economic reasoning.

\section{Cognition and the growth of knowledge}

The principle of biological evolution is genetic selection for features which contribute to inclusive fitness. These features include both physical and behavioural characteristics in a sorting process which necessarily extends over very many generations. The standard biological model therefore assumes a stable selection environment, and implies the possibility of extinction if there is an unfavourable environmental change; we should not therefore be surprised that only a very small proportion of the species which have appeared on earth have survived, or that species are disappearing at a high rate in the present era of environmental change, much of it the result, sometimes intended and sometimes not, of human activity. Our own species is not exempt from the possibility of extinction; but it does have a biological advantage in our distinctive, though limited, capability to recognise significant change and to develop new behaviours in response. This potential for learning may itself be interpreted as a biological adaptation to environments in which change is too rapid or too transitory to allow adequate genetic response through mutation and selection (Schlicht, 2000); it provides some real options to cope with the unexpected. 
This capability is not well represented by the economic concept of rationality, because its crucial feature is the cognitive potential to create new localised structures of classification and premisses for decision making, which in relation to the economic concept is pre-rational. The possibility of individual adaptation does not arise from the presence within the brain of a general purpose programme for system-wide optimisation or a universal strategy set in the game-theoretic sense of sequences of conditional actions that can be applied to all situations - which seems to be the conception tacitly underlying rational choice theory, especially when extended to rational expectations; instead an architecture of the brain which is appropriate for distributed programming allows sensory inputs to be assembled into distinctive patterns, each of which triggers effective actions, in the process of interaction with specific environments.

There are two linked evolutionary reasons for this architecture. The first is that genetic evolution proceeds by successive adaptations, each step of which has to be compatible with survival, and the step-by-step construction of a general problem-solving programme would entail many stages in which the use of the incomplete system would be likely to lead to disastrous mistakes. The second reason is that brain tissue has particularly high energy requirements, and the emergence of homo sapiens has been marked by a very substantial increase in brain size, and a consequent need to economise on energy demands. We should not therefore be surprised that a potential for multiple cognitive systems, each adapted to a limited function, and switched on only when required, was the naturally selected pathway to improved cognition, rather than a central processing system which would need to be permanently engaged. The division of labour is a fundamental principle of development, in the brain as well as in society; and the evolved network architecture of the brain made such a division possible.

These capabilities for adaptation were well advanced before the development of consciousness; and consciousness appears to have emerged, as one might expect, from this architecture and the functions that it supports. If the unconscious brain collects impressions into categories, and associates each category with a particular action, it is natural that consciousness should begin with awareness of some of these categories, and in particular with a perception that one of the categories presently employed is inadequate or linked to actions which are not effective. (The resemblance to the Carnegie language of aspirations and achievements is not accidental.) The response to dissatisfaction is then a search for better ways of ordering sensory impressions or for better connections between impressions and actions. We consciously try to make sense of our environment by imposing patterns upon it, seeking to improve upon tacit skills by codification, or by giving conscious direction to a process which remains beyond any detailed conscious control; and it is one of the most remarkable features of modern formal economics that its models of human behaviour make no reference to this characteristic activity of pattern making, both conscious and unconscious - even though modern 
formal economics is itself an impressive example of the drive to impose patterns. Consequently what is called 'rationality' within modern economics is a rather small, if important, part of human cognition, and makes a limited, if important, contribution to the explanation of human behaviour.

The two stages of development of human cognition which have just been outlined were presented as an evolutionary hypothesis in an early paper written by Alfred Marshall (1994) for a Cambridge discussion group. The significance of that paper for both the content and method of Marshall's subsequent work as an economist was identified by Tiziano Raffaelli (1994); and it has been suggested (Butler, 1991) that the motivation for writing it was supplied by a double crisis of religious and mathematical faith, the common feature of which was the perceived failure of axiomatic reasoning to guarantee empirical truth. The mathematical crisis was precipitated by the invention of non-Euclidean geometry: the point was not that Euclidean reasoning was wrong, or even inapplicable, but that its applicability was not ensured by the irrefutability of its logic. As Ziman (1978, p. 99) warns us, 'scientific knowledge cannot be justified or validated by logic alone'. This was also the lesson of Marshall's later encounter with Cournot's argument that falling costs entail monopoly - a lesson that was entirely lost amid the reinvention of Cournot's logic in the 1930s. Marshall's response was to apply Darwin's principles to sketch an evolutionary account of the growth of knowledge as structures of relationships. Caution in applying the patterns of axiomatic reasoning which had proved inadequate, and use of the evolutionary principles of the organisation of knowledge are persistent characteristics of his work as an economist.

More than a century earlier, David Hume had shown that it is impossible to prove any general empirical proposition, and turned to the question of how people acquired what we call knowledge. Marshall appears not to have read Hume's philosophical work - though he had studied Kant's response to it - nor Adam Smith's remarkable development of it in his psychological theory of the growth of science (1980), but he was later to make the connection with Smith's best-known application of his theory. As I have observed, the basic, and very powerful, skill of human cognition is the creation and application of patterns (of which logical reasoning is a special case); and Smith characterises scientific activity as the invention of 'connecting principles' which provide a credible account of relationships between phenomena. For this cognitive skill to be put to effective use it is important that people should be both sensitive to patterns and motivated to seek out or manufacture patterns. Not the least of the merits of Smith's analysis is the attention he gives to motivation, and what that motivation is. The driving force is the link between cognition and emotion.

Smith begins by identifying three human emotions: surprise, wonder (what we might now call perplexity) and admiration. An event or impression which does not conform to our expectations is surprising, and surprise causes discomfort. If we can find no way of accommodating it to our cognitive 
categories we are conscious of a failure to understand, which is at least disconcerting and may be dangerous; we therefore feel an urgent need to find a new way of making sense of our environment. "Wonder, therefore, and not any expectation of advantage from its discoveries, is the first principle which prompts mankind to the study of Philosophy, of that science which pretends to lay open the concealed connections that unite the various appearances of nature' (Smith, 1980, p. 51). From an evolutionary perspective, we can easily see that the emotive power of 'wonder', in Smith's sense, might sometimes be much more effective than 'an expectation of advantage' in promoting fitness-enhancing cognitive activity and thus improving adaptation to novel circumstances.

If we are successful, either through our own efforts or by adapting means which are already being used by someone else, in creating a new cognitive structure that seems to make sense, then our feeling of relief produces admiration in proportion to the discomfort, providing reinforcement to our new cognitive skill. Thus 'the repose and tranquillity of the imagination is the ultimate end of Philosophy' (Smith, 1980, p. 61); and because this repose and tranquillity rests on human inventions, rather than revelations of the principles that are actually in operation - even, Smith observes, when the invention has been made by Newton - it is always liable to further disturbance, which stimulates further invention. Hayek (1952) was later to note that the categories we use to order sensory impressions may differ substantially from the categories which have been developed to accommodate the development of corresponding scientific knowledge, and suggested an evolutionary explanation which is compatible with the argument of this section.

In a recent paper, Ekkehard Schlicht (2000) has associated both the motivation to resolve difficulties by inventing new patterns, and the criteria by which possible new patterns are assessed, with an aesthetic sense which, he suggests, often seems to take priority over more strictly instrumental concerns; as in Smith's analysis, an emotive drive may be more powerful than the prospect of practical benefits. Indeed, when people are consciously searching for a theory which will account for some puzzling phenomenon, or for an effective product design, they often work on the principle that 'if it looks right, it is right'. Schlicht provides some examples from modern science; and Smith's detailed account of the succession of cosmological theories incorporates repeated attention to the significance of aesthetic criteria, for example in the desire of Copernicus to incorporate the heavenly bodies within 'a new system, that these, the noblest works of nature, might no longer appear devoid of that harmony and proportion which discover themselves in her meanest productions' (Smith, 1980, p. 71). In explaining the triumph of Newtonian physics, Smith (p. 105) recognised the rhetorical power of its aesthetic appeal; and in his Lectures on Rhetoric he used this appeal in recommending that, in giving an account of some system, one should 'lay down certain principles ... from which we account for the several phenomena, connecting all together by the same chain' because 'the Newtonian 
method is undoubtedly the more philosophical, and in every science ... is vastly more ingenious and engaging' (Smith, 1983, p. 146). The incentives which both Smith and Schlicht emphasise do not coincide with the incentives to which economists typically give priority, though the latter may complement them; but they still appear to be important incentives to scientific investigation. In this, as in other aspects of its practice, science is still an art.

Smith went on to observe that as science progresses it tends to divide into specialisms, and these specialisms encourage attention to details which would otherwise not be noticed. Closer observation increases the chance of perceiving anomalies which provoke efforts to modify or replace patterns that would be acceptable to the non-expert; thus the division of labour within science leads to increases in scientific knowledge. Smith (1976a) founded his theory of economic development on this principle, in an exemplary demonstration of 'the Newtonian method'. We can now see that what underlies the unique potential of the division of labour within human society, in comparison with specialisation within any other species, is the architecture of the evolved human brain, which is capable in principle of forming any of an enormous variety of networks, far more than any single brain can actually sustain. By appropriate specialisation, therefore, a human community can generate far more knowledge than any single person is capable of. Marshall combined Smith's principle of the division of labour with Darwin's emphasis on variation in response to environmental differences, which had already been incorporated in Marshall's evolutionary hypothesis and underlay his insistence on the importance of variety among the firms in each industry. Economic development is the result of the division of labour, supplemented by variation within each field of knowledge, exploiting the capacity of the human brain to develop new cognitive networks and motivated by the human desire to make sense (and not just money) by imposing patterns. Marshall (1920, pp. 138-9) not only insisted on the importance of organisation as an aid to knowledge: he insisted on the distinctive contributions of different forms of organisation, for different connections are appropriate for different purposes.

\section{Institutions}

A necessary consequence of this process is the increasing interdependence of human society. Most of the knowledge and the skill that each person needs is held by others; and knowledge and skills are rarely re-usable without cost by those who do not already possess them. The lowest costs are typically incurred in acquiring knowledge within familiar fields from those who seem to be more knowledgeable, or by adopting the practices of those who seem to perform better. Willingness to borrow ideas and methods from others is a familiar human characteristic, explicable by its survival value (Schlicht, 2000). Nor is it difficult to understand why we should so often converge on a few models, as Smith realised; his psychological theory of science gives due attention to the factors affecting the diffusion of each cosmological system. 
Our cognitive limitations provide the incentives to borrow; the cognitive limitations of others, by impelling them to make and use patterns rather than attempting to optimise by using information that we cannot observe, make it easier to understand their rules of behaviour (Heiner, 1983); and our shared characteristics help us to imagine ourselves in someone else's situation and to tailor actions and communications to their perceptions, as Smith showed in both his Theory of Moral Sentiments (1976b) and his Lectures on Rhetoric (1983).

When we converge on rules for deciding how to behave, the shared conventions and procedures may be called 'institutions'; and our understanding of institutions is enhanced if we begin with an appreciation of human cognition, and the consequent advantages of adopting other people's procedures that seem to work for them, even when our actions have no effect on anyone else (Choi, 1993), rather than by postulating games between people without cognitive limitations. Schlicht's focus is on the conventions that facilitate interaction, and in particular on the criteria for a good rule, and this leads him to emphasise the importance of 'evaluations of an aesthetic kind, relating to formal features like symmetry, analogy, or good continuity' (Schlicht, 2000, p. 35). Such aesthetic evaluations are also important in choosing good rules for our private procedural rationality. As Schlicht points out, these features are not relevant to anyone who is deemed capable of optimising everything except the use of scant cognitive resources, but in a changing environment optimisation on each separate occasion is not a sensible objective, even by the criterion of overall optimisation. We may recall Schumpeter's proposition (1943, p. 83) that ' [a] system . . . that at every given point of time fully utilizes its possibilities to the best advantage may yet in the long run be inferior to a system that does so at no given point of time, because the latter's failure to do so may be a condition for the level or speed of long-run performance'. Schumpeter applied this proposition to 'any system, economic or other'; it is a proposition about uncertainty and discovery, which is as applicable to the individual as to the economy; indeed it is its applicability to the individual that underlies its application to the economy.

Schlicht identifies imitation (which is rarely a precise copy) as an effective mechanism for coping with changes which do not last long enough to permit adaptation at the genetic level, but long enough for knowledge which has been acquired by individual pattern making to be re-usable by others at relatively moderate cost. Sometimes this re-use may be formally organised. Frank Knight (1921), having defined 'uncertainty' as a situation in which no existing pattern or procedure is sufficient, and 'the entrepreneur' as someone who is willing to impose an interpretative framework on that situation, then suggests that an entrepreneur may find it quite easy to persuade people to accept his offer of employment rather than attempt to cope with uncertainty on their own. (Their motivation may well correspond to that on which Smith based his theory of scientific development.) The entrepreneur therefore exercises authority within his firm precisely in Barnard's sense (1938, 
p. 163), which locates the decision about which communications are authoritative with the recipient, not the source.

However, our analysis should indicate that authority is by no means restricted to hierarchical relationships, or even to relationships within formal organisations. Anyone whose instructions, advice, or example we accept in any particular context is a figure of authority within that context; and we would find it very hard to manage our lives without many such authorities. It is important to recognise the source of both institutions and authority in individual efforts to cope with individual cognitive problems and the urge to make sense of the complexity of our environment, because it provides a basis for understanding why the emergence of institutions which serve to co-ordinate interactions is often much easier than would be suggested by the multiplicity of equilibria in many game-theoretic models, and why people should be much readier to accept subordinate roles in organisations than might be expected from a model populated by cognitively self-sufficient agents. It also explains the effectiveness of marketing institutions which match cognitive needs.

\section{Markets}

A great deal of effort has been devoted by economists to examining the efficiency of exchange. However, it is not often that this examination begins by posing the question in an appropriately cognitive form: to what extent can the problems of differentiated knowledge be resolved through the exchange of knowledge which is embodied in goods and services? To do so immediately raises questions about the design of goods and services and also about the arrangements for exchange - or, in other words, about the working of markets. These are not necessarily distinct questions, for as Marshall (1919, p. 181) observed,

[p]roduction and marketing are parts of the single process of adjustment of supply to demand. The division between them is on lines which are seldom sharply defined: the lines vary from one class of business to another, and each is liable to modification by any large change in the resources of production, transport or the communication of intelligence.

New products may require the creation of new market institutions, and the possibility of creating new market institutions may suggest product redesign. I adopt Ménard's definition of a market as 'a specific institutional arrangement consisting of rules or conventions that make possible a large number of voluntary transfers of property rights on a regular basis' (1995, p. 170); and my focus is on the ways that these rules or conventions reduce the costs of transactions by simplifying cognitive tasks. We should also recognise the importance of transfers of knowledge that is not embodied in goods or services, and of arrangements for the development of knowledge, for these aspects of co-ordination are also often dependent on the working of markets. 
The markets to be considered are not, of course, the unanalysed markets of so much microeconomic - and of almost all macroeconomic - theory.

The failure to analyse markets as institutional arrangements which structure processes is a natural, and almost inevitable, consequence of choosing to start the analysis of exchange with perfect competition, for competition cannot be perfect unless every potential buyer has equal and costless access to every seller, and vice versa. The moment that one provides any structure to these market relationships competition is no longer perfect. The methodological necessity of avoiding structure accounts for the extraordinary status of the 'auctioneer' as the organiser of the perfect market (for which Walras has received undeserved blame): the auctioneer has neither preferences nor motivation, consumes no resources, is able to communicate with everyone without ever establishing any kind of personal contact and without cost to either party, and never makes a mistake; most extraordinary of all, the auctioneer is a monopolist who is trusted by everyone never to exploit his position, and always justifies this trust. Exactly the same characteristics are attributed to the 'social planner', who is subject to the same methodological necessity. Walrasian models are therefore dangerous guides to policy.

Since these perfect markets deliver efficient allocations without cost, it is not surprising that economists found some difficulty in explaining the existence of firms, which used resources in doing what the auctioneer did for nothing; nor is it surprising that Coase found it necessary to assume that economic agents, if not the auctioneer, incurred some costs in using markets. If Coase had been better trained in economic theory, he might have realised that costs of using markets would be difficult to reconcile with perfect competition, and responded by following Joan Robinson (1933) into her world of monopolies; if, however, he had been less well trained, or alternatively had been more familiar with the work of earlier economists, he might have addressed to markets the question that he posed about firms: if they cost something to operate, why are people willing to incur these costs? Markets should be explained, not assumed.

The route to an explanation was provided by Carl Menger (1976), who set out to analyse the structure of an economy as an increasingly complex system for meeting human needs. Beginning with goods which can be directly applied to their owners' needs, he introduced what was to become a characteristically Austrian concern with indirect ways of meeting these needs, such as making machines to make tools for growing crops which can then be turned into food. In this analytical system, the exchange of what one already possesses for something which can be used in the production chain is itself an indirect way of meeting needs. It is therefore not surprising, though it is significant, that Menger introduced exchange at the opposite end of the range from what had become the standard practice, with simple bilateral deals, and that he also recognised that making a deal incurs costs. A model of isolated exchanges but no market creates the possibility of explaining markets as a means for reducing the costs of exchange when there is a demand for multiple exchanges. 
In Menger's theoretical sequence it is the next step that is crucial. Rather than exchanging what they already have, some people may begin to use what they already have in the production of goods which are intended to be exchanged; and if that plan is successful, it may be worth while acquiring additional goods, not for use, but as inputs into regular production. Exchange now becomes an essential part of the business of improving one's condition, and the efficiency of the exchange process itself becomes a constraint on this improvement, and therefore a matter for attention. If the creation of a market can improve the efficiency of exchange, it is, in Menger's terms, a good of higher order, and its value is derived, in the first instance, from the value of the exchanges that it makes possible through this improvement in efficiency - and ultimately by the value of the indirect contribution that it makes to satisfying human needs.

The most obvious means of improving the efficiency of exchange is through the development of a generally accepted medium of exchange, which removes the need for direct barter. Menger concentrates on money, because it exemplifies the emergence of a pervasive institution as a result of individual initiative and the readiness of people to copy behaviour that seems to work effectively for others. In the course of developing this argument, he does, however, point out that goods differ substantially in their marketability - that is, in the costs which must be incurred in the process of exchange. Unless the producer has some special advantage, commodity production will be concentrated on goods with relatively high marketability, though, in accordance with Marshall's observation, a change in product design or production methods may be undertaken in order to improve marketability (canning and refrigeration provide two important examples). However, there are always some costs of exchange. Here the importance of indirect methods again comes to the fore, because the costs of achieving a single sale can often be substantially reduced by appropriate investment - by creating a set of institutions which constitute a market. The customer might pay for this investment, but would naturally need to be compensated by a lower price; and it is usually the producer who expects to be most dependent on particular categories of exchange who has the greater incentive to develop procedures which will facilitate exchange within those particular categories - in other words, to create a special market. Casson (1982, p. 163), who has given particular attention to the firm as market maker, provides a convenient summary of the obstacles to trade, and of the ways in which the producer may seek to overcome them: all these ways reduce the customer's cost of making a single transaction (and often the producer's cost of a single transaction) by a substantial initial commitment of resources.

The obstacles to trade discussed by Casson are primarily the result of deficiencies of knowledge; and so are the costs invoked by Coase (1937) to explain the creation of firms - though Coase did not see that firms make markets as well as goods. Both require knowledge to be organised; this is a cognitive issue, to be handled by procedural, not substantive, rationality. 
Costs per transaction are reduced by the development of a set of conventions about the way in which that transaction is to be carried out, including, for example, the location, the provision of information, opportunities to inspect or try out the product, standards for product characteristics, methods of payment, provision for servicing, and the commitments that are implicit in the deal. Because of the standard use of preference functions in consumer theory, it is important to mention that the use of money prices simplifies the assessment of each potential purchase; the 'measuring rod of money' is among the most important of conventions. The effect of these institutions is to ease the cognitive task of making a satisfactory purchase (and also the cognitive task of making a satisfactory sale). This cannot be achieved without a cognitive investment, and though the cost of this may fall mainly on the producer, customers must develop their own new routines. Everyone has to learn how to shop in a supermarket, how to buy through mail order, how to buy PEPs or ISAs, and now how to use the Internet effectively. This learning produces potentially re-usable knowledge; consequently everyone who makes this cognitive investment experiences the equivalent of what Penrose (1959) called 'the receding managerial limit' as new capabilities become embedded in new patterns of behaviour which release cognitive resources for other tasks, especially tasks that can incorporate the new routines. On the other hand, significant changes in institutional arrangements, such as the replacement of PEPs by ISAs and, on a much larger scale, the development of internet markets, impose new cognitive burdens.

The importance of simplifying the customer's cognitive task is illustrated by considering those markets in which many customers are willing to go to a good deal of trouble to get what they want, and where the common practice of supplier-fixed price does not apply. Three outstanding examples are the markets for houses, cars and many collectables. Here there are two powerful incentives for the customer to incur substantial transaction costs: purchases typically involve a substantial outlay, and they have substantial implications for the customer's style of living, and even for self-image. Such cognitive structures as lifestyle and self-image are a natural consequence of the patternmaking characteristics of the human brain which have been considered earlier, and the maintenance of these structures will normally be a major objective. It is therefore worth taking a good deal of trouble to ensure that any major purchase is compatible with the relevant patterns - or, occasionally, that an available purchase has sufficient appeal to justify some modification of those patterns. Rules for making such decisions have a substantial aesthetic component, even when the opinions of family, friends, colleagues, or neighbours are not of direct concern.

When there is substantial diversity among customers, the greatest reduction in transaction costs for a particular group may be achieved by the creation of sub-markets in which the rules and conventions, as well as the products, are precisely adapted to that group. This is yet another instance of the effects of the division of labour, which as always is limited by the extent of the market; 
but the extent of the market is influenced by the incremental cost of transacting in it. Firms, like individuals, differ in their capabilities, including their capabilities in devising institutional arrangements that are appropriate for particular groups of potential customers, and these differences are reflected in what they attempt and (even more) in what they achieve. But thinking of the ways in which firms can develop arrangements that enable them to sell more easily should not distract our attention from the contribution of these arrangements to the firm's knowledge about its business. They are an important part of what Marshall called its external organisation; and we have already drawn attention to the pervasive importance of externally organised knowledge to augment our own cognitive skills.

Market institutions are an important part of consumers' external organisation: the rules and conventions form part of their interpretative system and their framework for decision making. How we decide is not without influence on what we decide; and the power of market-making firms to shape the way that we decide seems to be well appreciated in many businesses, as is manifest in a brief observation of marketing strategy. This power is often attenuated by the efforts of rivals; as Hayek $(1948$, p. 106) pointed out, competition is a 'process of formation of opinion', or, in the language used earlier, a means of deciding whose communications will be provisionally accepted as authoritative. There is no choice without a framework, and as in Penrose's theory, the routinisation of procedures makes possible the acquisition or creation of new knowledge and new skills. If the process of transacting is easy, we can concentrate on what to transact, and how to develop new skills as consumers - or indeed as humans. Our cognitive resources, like the productive and managerial resources of the Penrosian firm, are capable of development, and when developed may deliver new productive services; we have therefore an incentive to learn about the possibilities and the opportunities (Penrose 1959, p. 77) - what we might call their 'option value'. We may be encouraged to do so by the recognition that the array of markets which we can use without much effort also has an option value for us: they allow us relatively easy access to a wide range of other people's capabilities.

We should not forget that the greater part of the value of transactions within a modern economy has no direct reference to final customers at all; and the same incentive to reduce the costs of individual transactions by substantial investment in developing appropriate institutions applies here. Business customers may have stronger incentives than do their suppliers to simplify the process of transacting, and this may not merely be a matter for the purchasing department, for production is closely linked with purchasing as well as marketing. Arrangements with suppliers may reduce the costs associated with production, and modifications to product and process may simplify relationships with suppliers. Amid the flurry of excitement about e-commerce, there have been several predictions that its impact may be greater on relations between businesses than on retailing; if this is so, it will 
be because of changes in the handling of transactions and also because of associated changes in the internal operations of firms.

\section{Conclusion}

We make sense of our situation by constructing order; the quality and applicability of our knowledge capital, as of physical capital, depend on its structure. But even in our private lives we are not dependent on our own resources: our common mental architecture makes it possible to connect to external knowledge capital, though by no means to all of it. Market relationships provide links that make possible the construction of additional knowledge and, by allowing many activities to be guided by rules and conventions, provide scope for imagination. Co-ordination by institutional arrangements defines boundaries, which should not lightly be assumed to match the fundamental data - this is not known anyway; but from a cognitive perspective it also defines a space to think within those boundaries, and even to make selective forays across them. The history of human development is one of discovering ways of circumventing the limits apparently imposed by the cognitive capacity of each individual, by an increasing division of cognitive labour and by developing procedures which enable us to make new combinations from the results of that division.

Market institutions not only release cognitive resources for the development of both consumer and organisational capital and therefore of new consumer demands and new productive opportunities which create new contexts for competition: particular institutional structures will encourage these developments to take particular forms. A study of the competitive process requires a study of the institutions within which it is channelled, and also of attempts to modify those institutions in ways that will favour the modifiers, not always with the effects intended. (Co-operative retail societies pioneered the development of supermarkets.) Indeed, we should not forget that much economic activity is devoted to the provision of market institutions and to the extension of market institutions to new classes of goods and services, illustrated by the diverse histories of Marks \& Spencer, Tesco and many providers of financial services, and also to the creation of new markets based on new institutional arrangements. The latter has recently appeared so important in its scale and possible effects that it has often been labelled 'the new economy'. We now have clear evidence that the creation of new institutions to gain competitive advantage may be very costly and that success is problematic; the new economy has not produced a new economics.

As with any innovation, acceptance depends on a combination of continuity and novelty that matches the perception of the customer, and it is easy to get this combination wrong. The competitive process combines ex-ante selection of what to offer and how to provide it by each competitor, based on premisses which are not a simple reflection of the basic data, but are defined from 'the imagined deemed possible' (Shackle, 1979, p. 26), and 
ex-post selection by customers who have their own notions about what will fit their own perceived needs. These notions are the product of cognitive, emotional and aesthetic factors, and change over time; the study of 'the active consumer' (Bianchi, 1998) is closely complementary to the study of competitive markets.

\section{References}

Barnard, C. A. (1938), The Functions of the Executive, Cambridge, MA, Harvard University Press.

Bianchi, M. (ed.) (1998), The Active Consumer, London, Routledge.

Butler, R. W. (1991), 'The historical context of the early Marshallian work', Quaderni di Storia dell'Economia Politica, 9(2-3), pp. 269-86.

Casson, M. (1982), The Entrepreneur: An Economic Theory, Oxford, Martin Robertson.

Choi, Y. B. (1993), Paradigms and Conventions: Uncertainty, Decision Making, and Entrepreneurship, Ann Arbor, University of Michigan Press.

Coase, R. H. (1937), 'The nature of the firm', Economica, new series, 4, pp. 386405.

Coase, R. H. (1991), 'The nature of the firm: influence', in Williamson, O. E. and Winter, S. G. (eds), The Nature of the Firm: Origins, Evolution and Development, Oxford, Oxford University Press, pp. 61-74.

Hayek, F. A. (1948), 'The meaning of competition', in Individualism and Economic Order, Chicago, University of Chicago Press, pp. 92-106.

Hayek, F. A. (1952), The Sensory Order, Chicago, University of Chicago Press.

Heiner, R. A. (1983), 'The origin of predictable behavior', American Economic Review, 73(4), pp. 560-95.

Knight, F. H. (1921), Risk, Uncertainty and Profit, Boston, MA, Houghton Mifflin. Reprinted Chicago, University of Chicago Press, 1971.

Marshall, A. (1919), Industry and Trade, London, Macmillan.

Marshall, A. (1920), Principles of Economics, London, Macmillan.

Marshall, A. (1994), 'Ye machine', Research in the History of Economic Thought and Methodology, Archival Supplement 4, Greenwich, CT, JAI Press, pp. 116-32.

Ménard, C. (1995), 'Markets as institutions versus organizations as markets? Disentangling some fundamental concepts', Journal of Economic Behavior and Organization, 28(2), pp. 161-82.

Menger, C. (1976 [1871]), Principles of Economics, trans. Dingwall, J. and Hoselitz, B. F., New York, New York University Press.

Penrose, E. T. (1959), The Theory of the Growth of the Firm, Oxford, Basil Blackwell; 3rd edn, Oxford, Oxford University Press, 1995.

Raffaelli, T. (1994), 'The early philosophical writings of Alfred Marshall', Research in the History of Economic Thought and Methodology, Archival Supplement 4, Greenwich, CT: JAI Press, pp. 53-159.

Robinson, J. V. (1933), The Economics of Imperfect Competition, London, Macmillan.

Schlicht, E. (2000), 'Aestheticism in the theory of custom', Journal des Economistes et des Etudes Humaines, 10(1), pp. 33-51.

Schumpeter, J. A. (1943), Capitalism, Socialism and Democracy, London, Allen \& Unwin. 
Shackle, G. L. S. (1979), Imagination and the Nature of Choice, Edinburgh, Edinburgh University Press.

Simon, H. A. (1976), Administrative Behaviours, 3rd edn (New York: Free Press).

Smith, A. (1976a), An Inquiry into the Nature and Causes of the Wealth of Nations, ed. Campbell, R. H., Skinner, A. S. and Todd, W. B., 2 vols, Oxford, Oxford University Press.

Smith, A. (1976b), The Theory of Moral Sentiments, ed. Raphael, D. D. and Macfie, A. L., Oxford, Oxford University Press.

Smith, A. (1980), 'The principles which lead and direct philosophical enquiries; illustrated by the history of astronomy', in Essays on Philosophical Subjects, ed. Wightman, W. P. D. and Bryce, J.C., Oxford, Oxford University Press, pp. 33-105.

Smith, A. (1983), Lectures on Rhetoric and Belles Lettres, ed. Bryce, J. C., Oxford, Oxford University Press.

Ziman, J. M. (1978), Reliable Knowledge, Cambridge, Cambridge University Press. 